\title{
EFFECT OF PARASITIC RESISTANCES AND DIODE IDEALITY FACTOR ON THE CHARACTERIZATION PARAMETERS OF PHOTOVOLTAIC MODULES: MATLAB SIMULATION STUDY
}

\author{
H. M. B. Metwally, M. A. Farahat, and A. A. A. Mehrem \\ Electrical Power Engineering Department, Faculty of Engineering, \\ Zagazig University, Zagazig, Egypt
}

\begin{abstract}
This paper studies the effects of series resistance, parallel resistance and diode ideality factor on photovoltaic module characterization parameters (short circuit current, open circuit voltage, fill factor and energy conversion efficiency). Parasitic resistances and diode ideality factor of the solar cell have an adverse impact on the cell performance, as these parameters increase the power losses in the cell and decrease the cell output power, FF and cell efficiency. This study shows that series resistance, parallel resistance and diode ideality factor have a significant effect on the photovoltaic performance. Therefore this effect can't be neglected and should be taken into account when using photovoltaic modules in different systems and when analyzing the module performance. Also this is useful for modeling process of PV modules, as the results are helpful in obtaining the best parameters values which match the datasheet parameters.

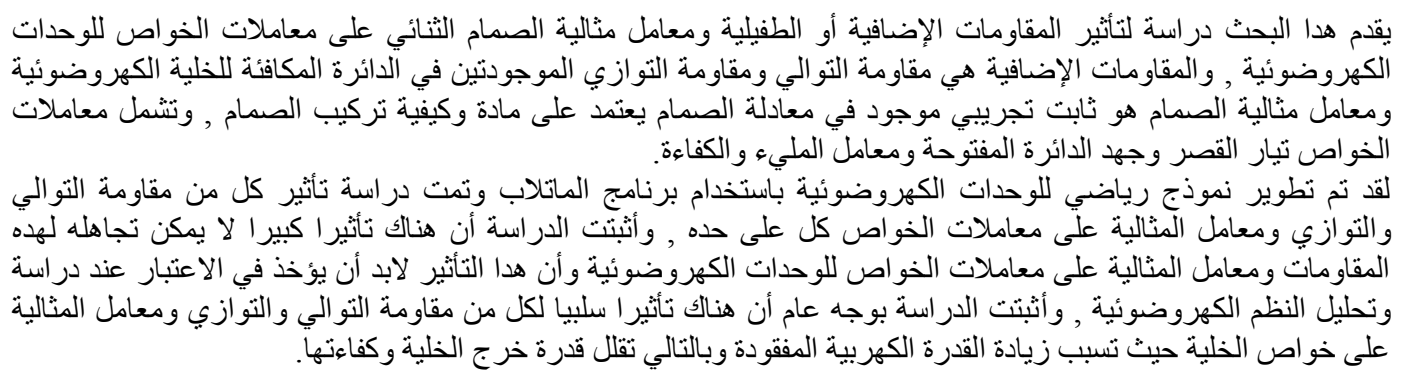

Keywords: Series resistance, Parallel resistance, Diode ideality factor, PV module, Modeling, Energy conversion efficiency.

\section{INTRODUCTION}

\subsection{PV Module Model}

Parameters that are used to characterize the solar cell output are called characterization parameters, such as $I_{s c}, V_{o c}, F F$ and $\eta$ [1]. The effects of $R_{s}, R_{p}$ and $n$ on these parameters can be adequately described by the more accurate model for PV cell which contains the following parameters.

\section{a) Series Resistance}

In a practical PV cell, there are many resistive losses in the current path through the semiconductor material, the metal grid, contacts and current collecting bus. These resistive losses are lumped together as a series resistor $(R s)$. In case of many cells connected in series the effect of this resistance becomes very conspicuous and its value must be multiplied by the number of cells[2].

\section{b) Parallel Resistance}

This is also called shunt resistance $(R p)$. It represents a loss associated with a small leakage of current through a resistive path in parallel with the intrinsic device [3].These are due to crystal damage and impurities in and near the junction. Using this resistance, the model gives a real behavior under the impact of shading on a string of cells wired in series [2]. Its effect is less conspicuous in a PV module compared to the series resistance, and it will become noticeable when a number of PV modules are connected in parallel for a larger system[4].

\section{c) Recombination}

Recombination in the depletion region of PV cells provides non-ohmic current paths in parallel with the intrinsic PV cell. This can be represented either by a second diode in the equivalent circuit with diode ideality factor equal two, or by a single diode with 
unknown diode ideality factor $(n)[2]$, thus the PV cell is usually represented by the single exponential (diode) model or the double exponential (diode) model[5].

The single exponential circuit model is shown in Figure 1. This model contains five parameters $I_{s c}, I_{o}$, $R_{s}, \quad R_{p}$ and $n$ (Eq. 1)[2].The values of these parameters must be determined to reproduce the $I-V$ curve.

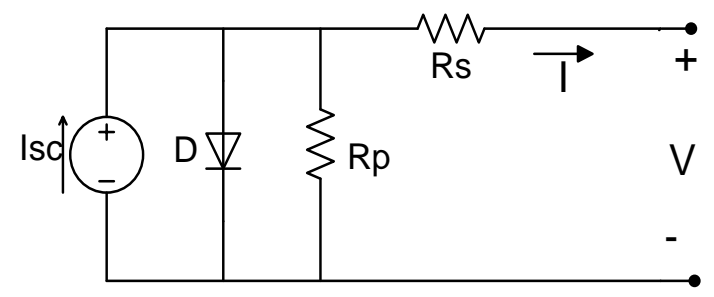

Fig. 1 Equivalent circuit used in the MATLAB simulations

The current-voltage relationship of the PV cell is [2]:

$$
I=I_{s c}-I_{o}\left[e^{\left(\frac{V+I R_{s}}{n V_{T}}\right)}-1\right]-\left(\frac{V+I . R_{s}}{R_{p}}\right)
$$

The thermal voltage $\left(V_{T}\right)$ is given by:

$$
V_{T}=\frac{k T}{q}
$$

The strategy of modeling a PV module is not different from modeling a PV cell. It uses the same PV cell model. The parameters are the same, but only a voltage parameter (such as the open-circuit voltage) is different and must be divided by the number of cells. This study uses the single diode model, shown in Figure(1), which provides fairly accurate results. The model consists of a current source (Isc), a diode $(D)$ with diode ideality factor $(n)$ set to achieve the best $I-V$ curve match and its value varies from one to two depending on the material and the physical construction of the cell[6], a series resistance $(R s)$ and a parallel resistance $\left(R_{p}\right)$.

\subsection{Fill Factor $(\boldsymbol{F F})$}

The fill factor is a quantity that is often used to characterize module performance. The fill factor is the ratio of the power at the maximum power point to the product of $V_{o c}$ and $I_{s c}$.

$$
F F=\frac{\text { Maximum } \text { Power }}{V_{O C} \cdot I_{S C}}=\frac{V_{m p p} \cdot I_{m p p}}{V_{O C} \cdot I_{S C}}
$$

The fill factor is directly affected by the module parameters such as $R_{S}, R_{P}$ and $n$ [7].

\subsection{Energy Conversion Efficiency $(\eta)$}

The energy conversion efficiency of solar cell is the ratio of the maximum electrical power output from the cell to the solar power impinging the cell. This ratio is calculated at $S T C\left(1000 \mathrm{~W} / \mathrm{m}^{2}, 25^{\circ} \mathrm{C}\right.$ and 1.5 A.M). Mathematically, the cell efficiency is given by:

$$
\begin{gathered}
\eta=\frac{\text { Maximum Output Power }}{\text { solar power impinging the module }} \\
=\frac{V_{m p p} \cdot I_{m p p}}{G \cdot A}
\end{gathered}
$$

Energy conversion efficiency of PV module in terms of fill factor:

$$
\eta=\frac{F F \cdot V_{O C} \cdot I_{S C}}{G \cdot A}
$$

The actual silicon cell efficiency is roughly in the range of $20-25 \%$ [4].

\section{MODELING A PV MODULE BY MATLAB}

Kyocera KC-120-1 PV module is chosen for a MATLAB simulation model. The module consists of 36 multi-crystalline silicon solar cells in series and provides $120 \mathrm{~W}$ of nominal maximum power [8]. The MATLAB model gives a good correspondence between the data points and the simulated $I$ - $V$ curves as shown in figure 2, the discrete points are taken from the datasheet while the continuous lines are obtained by simulation. The series and parallel resistances are calculated by MATLAB model for the chosen module, such that $R_{s}=4.7 \mathrm{~m} \Omega$ and $R_{p}=$ 2.9953 $\Omega$. By trial and error, and using MATLAB model, it was found that $n=1.05$, is the best value that attains the best match with the $I-V$ curve on the datasheet. At STC the energy conversion efficiency of the chosen module can be calculated from equation(6), and the $F F$ of the chosen module is $75 \%$.

$$
\eta=\beta \times P_{m}
$$

where $\beta=1 /(G . A)$, and equal to $0.1076 \mathrm{~W}^{-1}$ at $S T C$.

\section{EFFECT OF SERIES RESISTANCE}

In the following, the part of the $I-V$ curve from the short circuit point to the MPP will be called the voltage-controlled part while the part from the open circuit point to the MPP will be called the currentcontrolled part. Figure 3 shows the effect of series resistance on the $I-V$ and $P-V$ curves of the chosen module. In this study, the series resistance is changed from zero (as the ideal value) to $20 \mathrm{~m} \Omega$ (as a worse practical value) in steps $5 \mathrm{~m} \Omega$. Parallel resistance and diode ideality factor are kept constant at $2.9953 \Omega$ and 1.05 respectively. As series resistance increases, the voltage drop between the diode voltage and the terminal voltage becomes greater for the same current. The result is that the current-controlled portion of the $I-V$ curve begins to sag towards the vertical axis, producing a significant decrease in the terminal voltage $V$ and a slight reduction in $I_{s c}$, and have no effect on $V_{o c}$. 


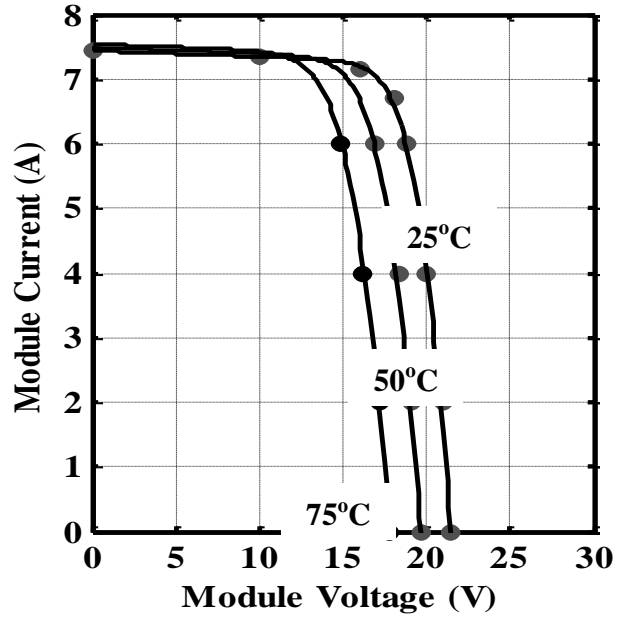

(a)

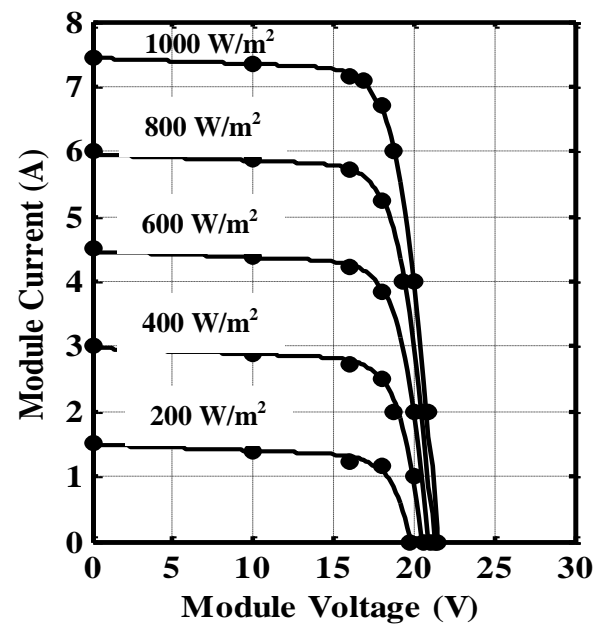

(b)

Fig. 2 I-V curves of KC-120-1 PV module (a) At different temperature and $1 \mathrm{~kW} / \mathrm{m}^{2}$

(b) At different irradiance intensity and $25^{\circ} \mathrm{C}[8]$

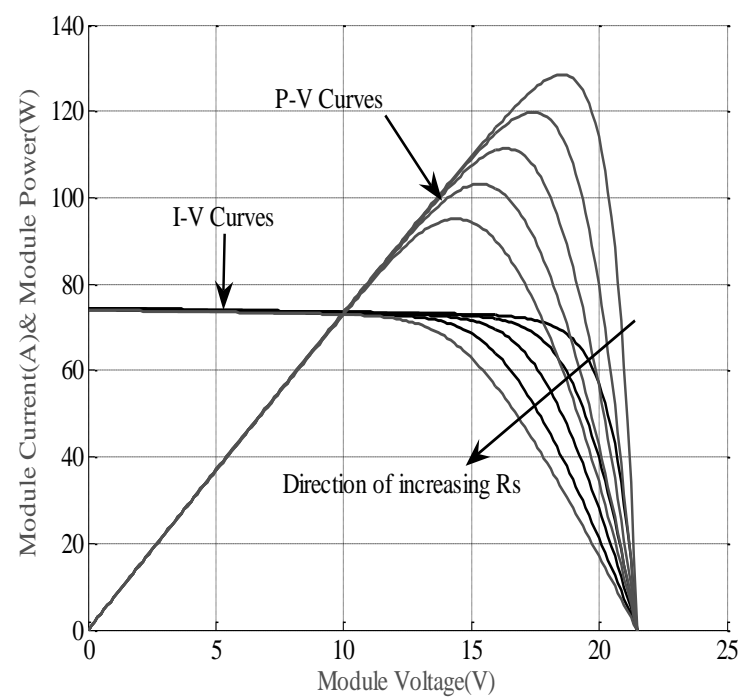

Fig. 3 Effect of series resistance on $I-V \& P$ - $V$ curves at $1 \mathrm{~kW} / \mathrm{m}^{2}, 25^{\circ} \mathrm{C}, n=1.05$ and $R_{p}=2.9953 \Omega$ (Note: current is multiplied by 10 )
3.1 Effect of $R_{s}$ on $V_{o c}$

Figure 4 shows the effect of series resistance on $V_{o c}$ which indicates that, the series resistance have no effect at all on $V_{o c}$.(note: cases 1 and 2 are identical).

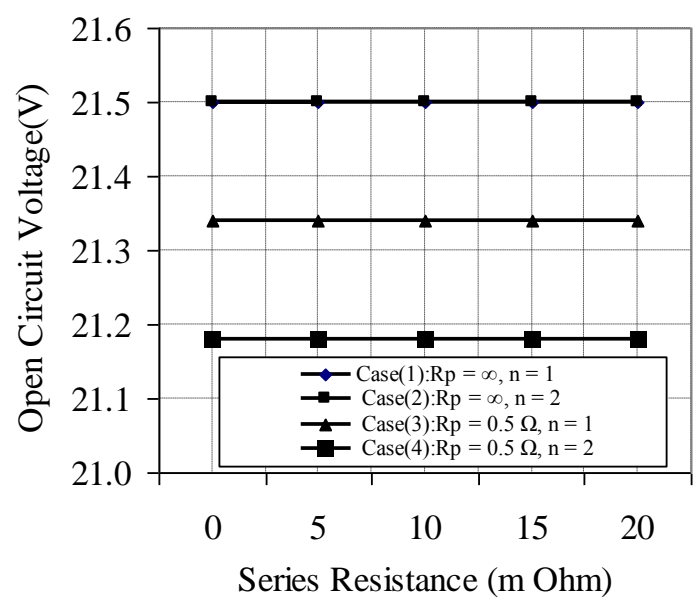

Fig. 4 Effect of series resistance on $V_{o c}$ at STC

\subsection{Effect of $\boldsymbol{R}_{s}$ on $\boldsymbol{I}_{s c}$}

Figure 5 shows the effect of series resistance on $I_{s c}$ which indicates that, For large values of $R_{p}$, series resistance have no effect on $I_{s c}$. But for small value of $R_{p}$, the $I_{s c}$ slightly decreases linearly as increasing $R_{s}$. (note: cases 1 and 2 are identical and so cases 3 and 4).

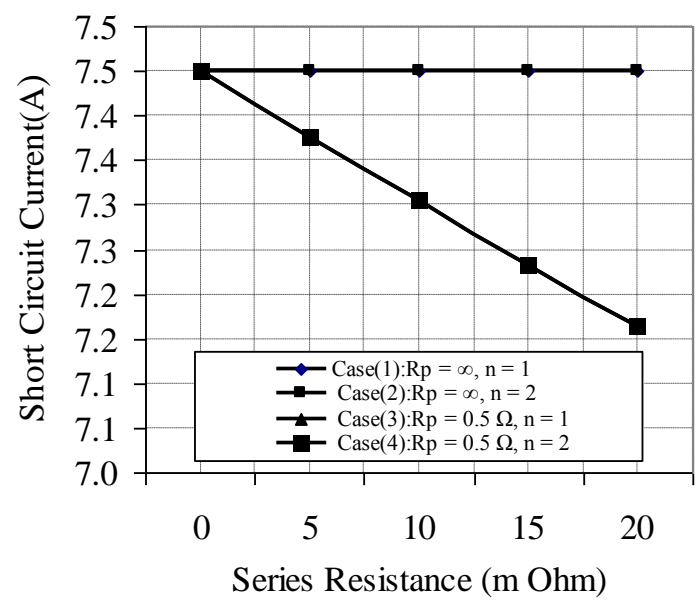

Fig. 5 Effect of series resistance on $I_{s c}$ at STC

\subsection{Effect of $\boldsymbol{R}_{s}$ on $F F$}

Figure 6 shows the effect of series resistance on $F F$ which indicates that, in general the $F F$ decreases significantly as $R_{s}$ is increased. But the rate of decline for small value of $R_{p}$ is less than that for large value. And the diode ideality factor almost have no effect on the rate of decline. 


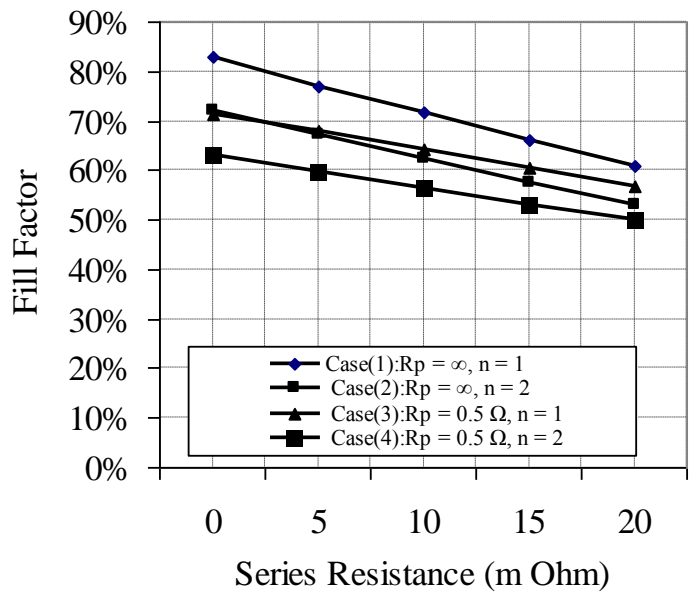

Fig. 6 Effect of series resistance on $F F$ at STC

\subsection{Effect of $R_{s}$ on $\eta$}

Figure 7 shows the effect of series resistance on the efficiency of the chosen module which indicates that, the effect of $R_{s}$ on $\eta$ is very similar to that of $R_{s}$ on $F F$.

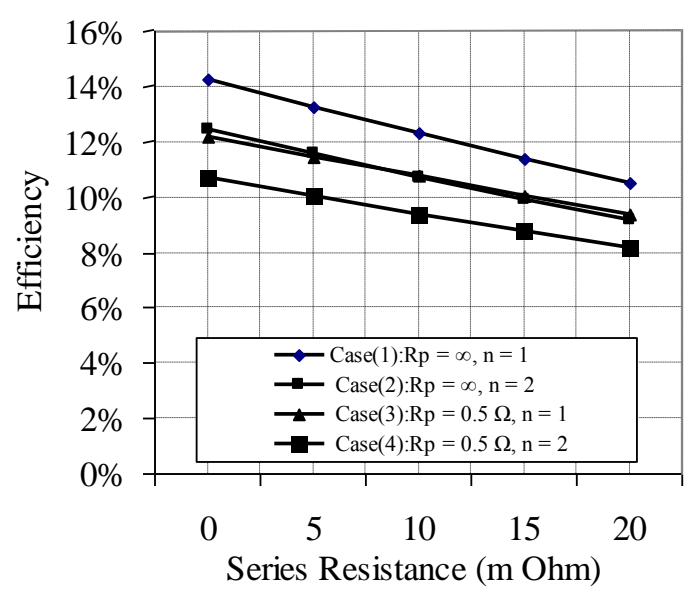

Fig. 7 Effect of series resistance on $\eta$ at STC

\section{EFFECT OF PARALLEL RESISTANCE}

Figure 8 shows the effect of the parallel resistance on the $I-V$ and $P-V$ curves of the chosen module. In this study, the parallel resistance is changed from infinity (as the ideal value) to $0.3 \Omega$ (as a worse practical value). Series resistance and diode ideality factor are kept constant at $4.7 \mathrm{~m} \Omega$ and 1.05 respectively (the calculated values of the chosen module). As parallel resistance decreases, the current diverted through the shunt resistor increases for a given level of diode voltage. The result is that the voltage-controlled portion of the $I-V$ curve begins to sag towards the horizontal axis, producing a significant decrease in the terminal current $I$ and a slight reduction in $V_{o c}$ and $I_{s c}$. Very low values of $R_{p}$ will produce a significant reduction in $V_{o c}$ and $I_{s c}$.

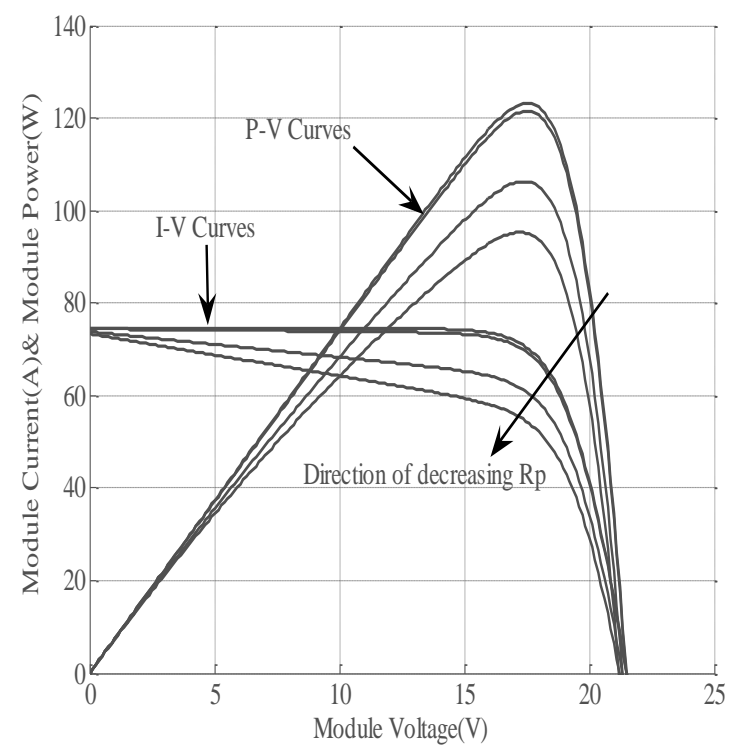

Fig. 8 Effect of parallel resistance on $I-V \& P-V$ curves at $1 \mathrm{~kW} / \mathrm{m}^{2}, 25^{\circ} \mathrm{C}, \mathrm{n}=1.05$ and $\mathrm{Rs}=4.7 \mathrm{~m} \Omega$ (Note: current is multiplied by 10 )

\subsection{Effect of $R_{p}$ on $V_{o c}$}

The effect of parallel resistance on the $V_{o c}$ is shown in figure 9. In general, $V_{o c}$ decreases as decreasing $R_{p}$. But for large values $R_{p}$, the decrease in of $V_{o c}$ is very small and can be neglected. On the other hand, for small values of $R_{p}$ there is a noticeable decrease in $V_{o c}$. And for $n=2$ the decreasing and also the rate of decline in $V_{o c}$ become larger, but this effect can be neglected in large values of $R_{p}$, but it must be taken into account for small values (note: cases 1 and 3 are identical and so cases 2 and 4 ).

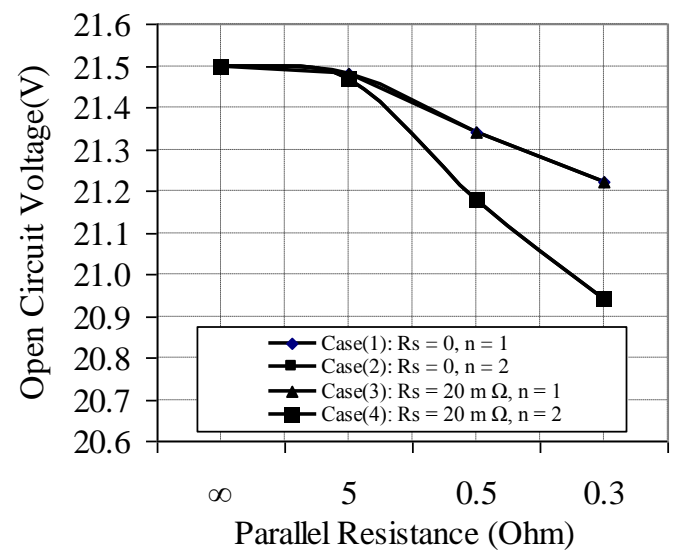

Fig. 9 Effect of parallel resistance on $V_{o c}$ at STC

\subsection{Effect of $R_{p}$ on $I_{s c}$}

Figure 10 shows the effect of parallel resistance on $I_{s c}$ which indicates that, $R_{p}$ has no effect on $I_{s c}$ except for large value of $R_{s}$, where the short circuit current decreases as $R_{p}$ is decreased. And this reduction becomes significant for small values of $R_{p}$. (note: cases 1 and 2 are identical and so cases 3 and 4 ). 


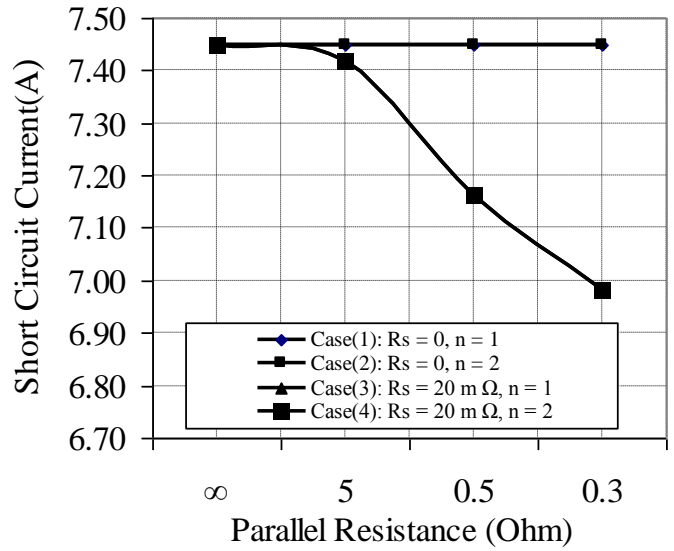

Fig. 10 Effect of parallel resistance on $I_{s c}$ at STC

\subsection{Effect of $\boldsymbol{R}_{p}$ on $\mathrm{FF}$}

The effect of parallel resistance on $F F$ is shown in figure 11. In general $F F$ decreases as decreasing $R_{p}$, and this effect becomes larger for large values of $R_{p}$ ,than small values. Adding the effect of $n$ will decrease the $F F$ more, but doesn't affect the rate of decline. Unlike $R_{s}$, which decrease the $F F$ and decrease the rate of decline.

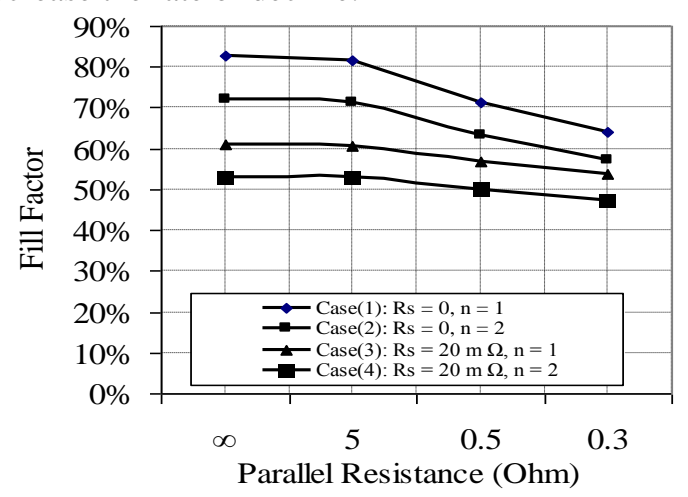

Fig. 11 Effect of parallel resistance on $F F$ at STC

\subsection{Effect of $R_{p}$ on $\eta$}

Figure 12 shows the effect of parallel resistance on the efficiency. The effect of $R_{p}$ on $\eta$ is very similar to that of $R_{p}$ on $F F$.

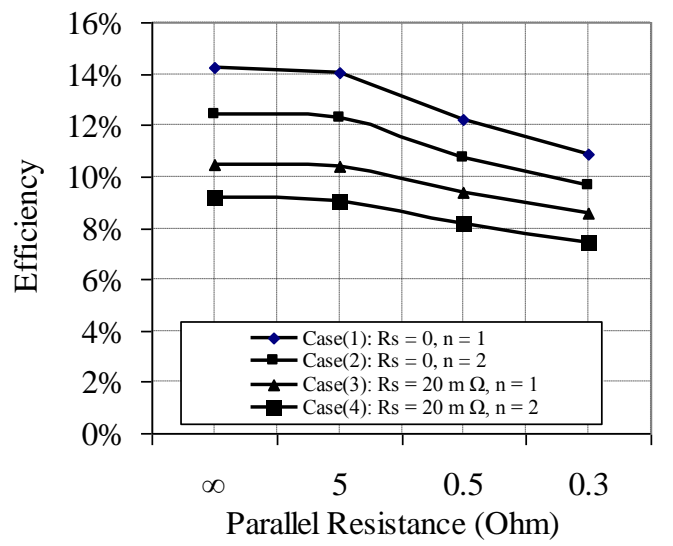

Fig. 12 Effect of parallel resistance on $\eta$ at STC

\section{EFFECT OF DIODE IDEALITY FACTOR}

The ideality factor is a fitting parameter that describes how closely the diode's behavior matches that predicted by theory, which assumes the p-n junction of the diode is an infinite plane and no recombination occurs within the space-charge region. A perfect match to theory is indicated when $n=1$, But when recombination in the space-charge region dominates other recombination, then $n=2$ [7]. The effect of changing ideality factor on the $I-V$ and $P-V$ curves of the chosen module is shown in Figure 13. In this study, the diode ideality factor is changed from one (as the ideal value) to two (as the worse value). Series and parallel resistances are kept constant at $4.7 \mathrm{~m} \Omega$ and $2.6653 \Omega$ respectively (the calculated values of the chosen module). As the ideality factor increases from one to two, the voltagecontrolled portion of the $I-V$ curve begins to sag towards the origin at the knee region, producing a slight reduction in $V_{o c}$, and have no effect on $I_{s c}$.

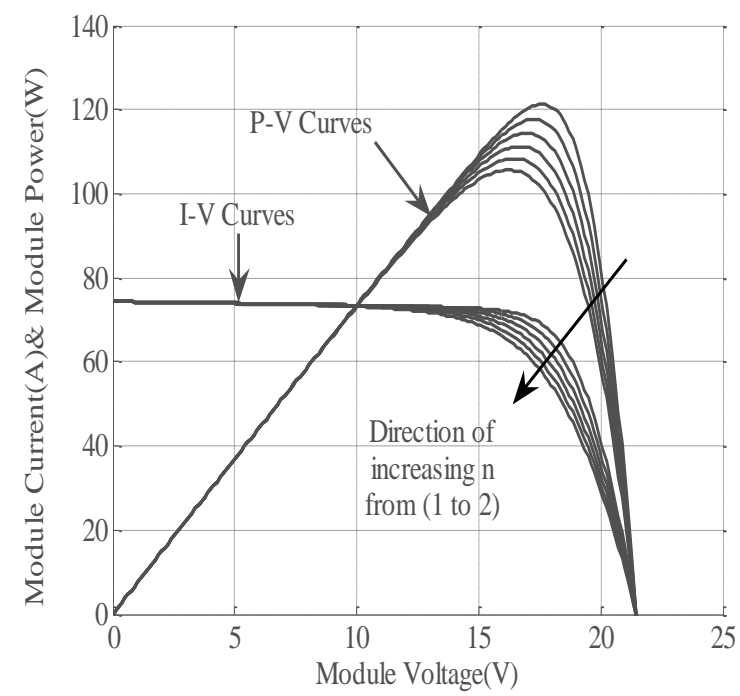

Fig. 13 Effect of diode ideality factor on $I-V \& P-V$ curves at $1 \mathrm{~kW} / \mathrm{m}^{2}, 25^{\circ} \mathrm{C}, \mathrm{R}_{\mathrm{p}}=2.9953 \Omega$ and $\mathrm{Rs}=4.7$ $\mathrm{m} \Omega$ (Note: current is multiplied by 10 )

\subsection{Effect of $\boldsymbol{n}$ on $\boldsymbol{V}_{\boldsymbol{o c}}$}

Figure 14 shows the effect of diode ideality factor on $V_{o c}$ which indicates that, $n$ has no effect on $V_{o c}$ except for low value of $R_{p}$, where the open circuit voltage decreases as the diode ideality factor is increased (note: cases 1 and 2 are identical and so cases 3 and 4). 


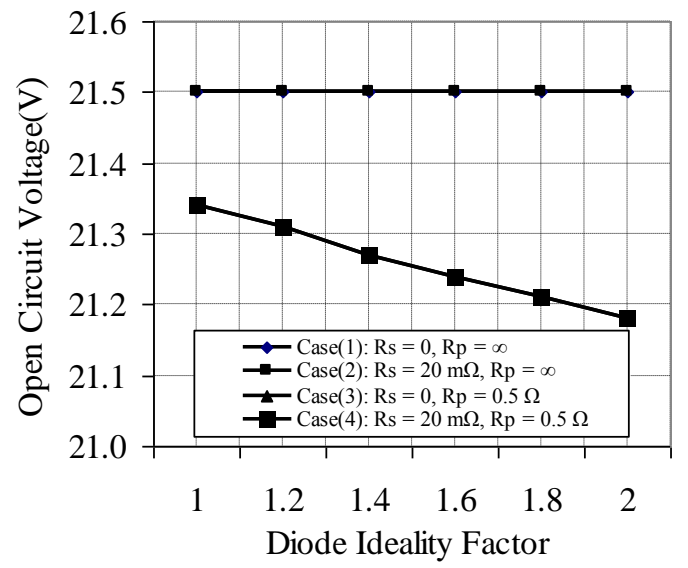

Fig.14 Effect of diode ideality factor on $V_{o c}$ at STC

\subsection{Effect of $\boldsymbol{n}$ on $\boldsymbol{I}_{\boldsymbol{s c}}$}

Figure 15 shows the effect of diode ideality factor on $I_{s c}$. It can be seen that the diode ideality factor has no effect at all on $I_{s c}$ (note: cases 1,2 and 3 are identical).

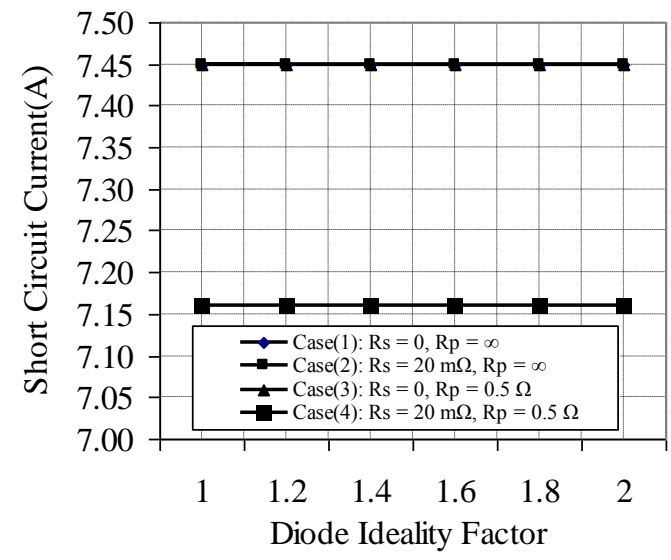

Fig. 15 Effect of diode ideality factor on $I_{s c}$ at STC

\subsection{Effect of $\boldsymbol{n}$ on $\boldsymbol{F F}$}

The effect of diode ideality factor on $F F$ is displayed in Figure 16. There is a general decrease in fill factor as the ideality factor is increased.

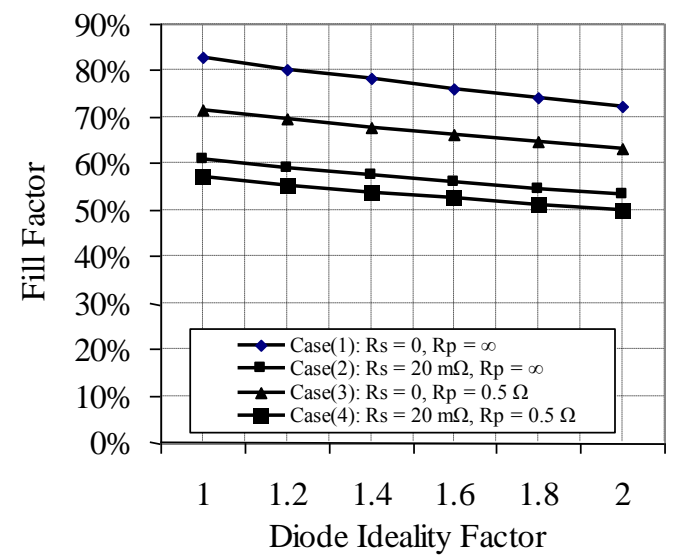

Fig.16 Effect of diode ideality factor on $F F$ at STC

\subsection{Effect of $n$ on $\eta$}

Figure 17 shows the effect of diode ideality factor on the efficiency which indicates that, the effect of ideality factor on the efficiency is very similar to that of ideality factor on the fill factor.

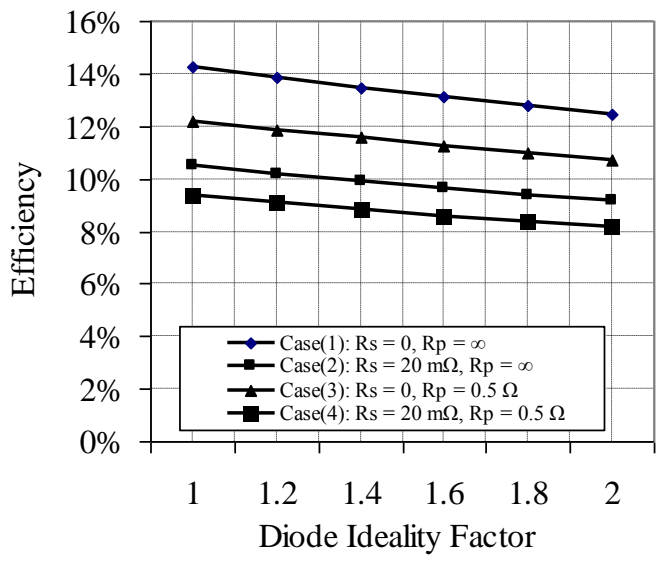

Fig. 17 Effect of diode ideality factor on the efficiency at STC

\section{CONCLUSIONS}

In this paper, the effects of parasitic resistances and diode ideality factor on characterization parameters of Photovoltaic modules are studied and from the results obtained the following points are concluded:

- Most influential parameter on $V_{\mathrm{oc}}$ is the parallel resistance, where $V_{o c}$ decreases as $R_{p}$ is decreased, and this impact increases for small values of $R_{p}$. Increasing the diode ideality factor produces a slight reduction in $V_{o c}$ in the presence of $R_{p}$ only. On the other side, the series resistance doesn't have effect on $V_{o c}$ at all.

- The short circuit current influenced only in the presence of $R_{s}$ and $R_{p}$ with each other. Where $I_{s c}$ decreases as decreasing $R_{p}$, and this effect increases with small values of $R_{p}$. and $I_{s c}$ decreases linearly as increasing $R_{s}$. On the other side, the diode ideality factor doesn't have effect on $I_{s c}$ at all.

- In general all parameters affect on $F F$, such that, increasing $n$ or $R_{s}$ will decrease $F F$ linearly, and decreasing $R_{p}$ will decrease $F F$ but irregularly, where the rate of decline increases at small values of $R_{p}$. In general also, any combination between $R_{s}$ and $R_{p}$ will decrease the rate of decline of $F F$, when one parameter being changed and the other is kept constant.

- Reference to equation(5), it's noted that the efficiency is dependant on $F F$, and reference to the curves, it's noted that the effect of parameters on $\eta$ is very similar to that on $F F$.

- Any change in these parameters have a major impact on the tendency of $I-V$ curves, where $R_{s}$ and $n$ affect only the slop of $I-V$ curves near $V_{o c}$. And $R_{p}$ has a significant effect on the slop of $I-V$ curves near $I_{s c}$, and a slight effect on it near $V_{o c}$. 
- Reference to equation(6), it's noted that the value of the maximum power is directly proportional to the efficiency. And reference to the curves, the maximum power take the same behavior as the efficiency with the change of these parameters.

- Change these parameters have a major impact on the location of $M P P\left(V_{m p p}\right)$, where $R_{s}$ have the greatest influence on the location of $M P P$, where a slight increase in $R_{s}$, produce a significant decrease in $V_{m p p}$. But the impact of $n$ and $R_{p}$ on $V_{m p p}$ can be neglect.

\section{APPENDIX}

A. List of symbols

$n \quad$ diode ideality factor, dimensionless

$R_{S} \quad$ series resistance, $\Omega$

$R_{p} \quad$ parallel resistance, $\Omega$

I output current of solar cell, A

$I_{s c} \quad$ short-circuit current, A

Io reverse saturation current, A

$I_{m p p} \quad$ output current of solar cell at maximum power point, A

$V_{T} \quad$ thermal voltage, $\mathrm{J} / \mathrm{C}$

STC Standard test conditions

$\eta \quad$ Energy Conversion Efficiency

$G$ intensity of radiation, $\mathrm{W} / \mathrm{m}^{2}$

$V \quad$ output voltage of solar cell, $\mathrm{V}$

$V_{o c} \quad$ Open circuit voltage, $\mathrm{V}$

$V_{m p p} \quad$ output voltage of solar cell at maximum power point, $\mathrm{V}$

$P_{m} \quad$ maximum power, $\mathrm{W}$

$T \quad$ cell temperature, $\mathrm{K}$ $k$ boltzmann's constant, $1.381 \times 10^{-23} \mathrm{~J} / \mathrm{K}$

$q \quad$ electron charge, $1.602 \times 10^{-19} \mathrm{C}$

$F F \quad$ Fill factor

A.M Air mass

$A \quad$ Module cross-section area, $\mathrm{m}^{2}$

$\beta \quad$ Constant, $0.1076 \mathrm{~W}^{-1}$ at $S T C$

\section{REFERENCES}

[1] Foster F. and Ghassemi M. "Solar Energy: Renewable Energy and the Environment", Univ. of New Mexico. Energy and Environment Series, (2009).

[2] Akihiro Oi. "Design and Simulation of Photovoltaic Water Pumping System", M.Sc. Thesis, Univ. of California Polytechnic, (2005).

[3] Castañer L. and Silvestre S. "Modeling Photovoltaic Systems, Using PSpice", John Wiley \& Sons Ltd, 2002.

[4] Masters G. M. "Renewable and Efficient Electric Power Systems", John Wiley \& Sons Ltd, 2004.

[5] Betka A. "Perspectives for the Sake of Photovoltaic Pumping Development in the South", M.Sc. Thesis, Unvi. of Batna, (2002).

[6] Rashid M. "Power Electronics - Circuits, Devices and Applications" $3^{\text {rd }}$ Edition Pearson Education, 2004.

[7] http://en.wikipedia.org/wiki/Solar_cell\#The_pn_junction.

[8] Kyocera KC120-1 Multi-crystalline Photovoltaic Module Datasheet, 2001. 